\title{
AN OVERVIEW OF THE USE OF EXTREMITY DOSEMETERS IN SOME EUROPEAN COUNTRIES FOR MEDICAL APPLICATIONS
}

\author{
L. Donadille ${ }^{1, *}$, E. Carinou ${ }^{2}$, M. Ginjaume ${ }^{3}$, J. Jankowski ${ }^{4}$, A. Rimpler 5 , M. Sans Merce ${ }^{6}$ and F. Vanhavere ${ }^{7}$ \\ ${ }^{1}$ Institut de Radioprotection et de Sûreté Nucléaire (IRSN), BP 17, 92262 Fontenay-aux-Roses Cedex, \\ France \\ ${ }^{2}$ Greek Atomic Energy Commission (GAEC), Ag. Paraskevi, Attiki, Greece \\ ${ }^{3}$ Institut de Tècniques Energètiques, Universitat Politècnica de Catalunya (UPC), Diagonal 647, 08028 \\ Barcelona, Spain \\ ${ }^{4}$ Nofer Institute of Occupational Medicine (IOM), St Teresa Street 8, 90-950 Lodz, Poland \\ ${ }^{5}$ Bundesamt für Strahlenschutz (BfS), Köpenicker Allee 120-130, 10312 Berlin, Germany \\ ${ }^{6}$ Institut Universitaire de Radiophysique Appliquée (IRA), rue du Grand Pré 1, 1007 Lausanne, Switzerland \\ ${ }^{7}$ Belgian Nuclear Research Centre (SCK-CEN), Boeretang 200, 2400 Mol, Belgium
}

\begin{abstract}
Some medical applications are associated with high doses to the extremities of the staff exposed to ionising radiation. At workplaces in nuclear medicine, interventional radiology, interventional cardiology and brachytherapy, extremities can be the limiting organs as far as regulatory dose limits for workers are concerned. However, although the need for routine extremity monitoring is clear for these applications, no data about the status of routine extremity monitoring reported by different countries was collected and analysed so far, at least at a European level. In this article, data collected from seven European countries are presented. They are compared with extremity doses extracted from dedicated studies published in the literature which were reviewed in a previous publication. The analysis shows that dedicated studies lead to extremity doses significantly higher than the reported doses, suggesting that either the most exposed workers are not monitored, or the dosemeters are not routinely worn or not worn at appropriate positions.
\end{abstract}

\section{INTRODUCTION}

According to the Council Directive 96/29/EURATOM of the European Union ${ }^{(1)}$, which is based on the recommendations of the $\operatorname{ICRP}^{(2)}$, if the dose to any part of the extremities of a worker is likely to exceed threetenths of the annual dose limit, an additional dosemeter should be worn on the part of the extremity where the dose is expected to have its highest value. In practice, extremity monitoring is carried out by measuring the personal dose equivalent $H_{\mathrm{p}}(0.07)^{(3)}$, considering it as an estimator of the equivalent dose to the skin for which the annual limit is $500 \mathrm{mSv}$.

The requirement of finding the area of skin where the dose is maximum is one of the main problems of extremity monitoring and causes severe practical difficulties. In daily practice, when preparing and administering radiopharmaceuticals in nuclear medicine (NM), or participating in a complex radiological intervention in interventional radiology/interventional cardiology (IR/IC), it is not easy to know which part of the hand will receive the highest dose. Moreover, the dose distribution across the hand may vary during a single process as well as when various persons perform the same procedure. Another difficulty is that the dosemeter should not disturb manipulations carried out by the medical staff, it has

*Corresponding author: laurent.donadille@irsn.fr to be compatible with the wearing of gloves and, if needed, with sterilisation protocols. Also, the dosemeter has to be adapted to the encountered radiation fields. For these reasons extremities, and particularly hands, are difficult to monitor.

The objective of EURADOS Working Group 9 (WG9) (funded by the European Commission, through the CONRAD project) was to promote and coordinate research activities for the assessment of occupational exposures to medical staff. Sub-group 1 (SG1) of WG9 dealt with extremity dosimetry of workers in IR, IC, NM and brachytherapy (BT). These activities involve either the direct handling of highly active $\mathrm{X}, \gamma$ or $\beta^{+/-}$sources (e.g. ${ }^{99 \mathrm{~m}} \mathrm{Tc},{ }^{201} \mathrm{Tl}$, ${ }^{131} \mathrm{I},{ }^{18} \mathrm{~F},{ }^{90} \mathrm{Y}$ in NM, ${ }^{192} \mathrm{Ir},{ }^{137} \mathrm{Cs}$ in $\left.\mathrm{BT}\right)$, or working close to an X-ray radiation field (typically $60-100 \mathrm{kV}$ filtered X-rays in IR and IC).

The tasks undertaken by SG1 were to perform (i) an intercomparison of relevant extremity dosimetry techniques; (ii) a thorough literature review of dedicated studies; and (iii) an overview of the use of extremity dosemeters in some European countries. The results of the intercomparison and the literature review have been published ${ }^{(4,5)}$, see also reference ${ }^{(6)}$. This article deals with the third task, the dosimetric data overview.

Data related to the use of extremity dosemeters in the medical field were collected from seven countries. They are presented and compared with the doses extracted from the literature review. 


\section{METHOD}

Extremity dosimetry data were collected from seven countries: Switzerland, Germany, Spain, France, Greece, Ireland and Poland. They were provided by the central register of each country, except for France and Poland. The data for France have been obtained from different dosimetry services, nevertheless representing all monitored workers. For Poland, they come from one dosimetry service, representing the majority of the workers monitored for extremities.

The development of extremity dosimetry has been substantially different in the seven chosen countries. As regards, the position and type of dosemeter (Table 1), Spain and France perform extremity dosimetry using wrist or ring dosemeters, depending on the dosimetry service. Nevertheless wrist dosemeters are more widely used than ring ones in these two countries. Switzerland, Germany, Ireland and Poland only use ring dosemeters, whereas in Greece, wrist dosemeters were used until 2006 and from 2007 ring dosemeters have been introduced. The monitoring period is 1 month for all seven countries. As mentioned earlier, the dosemeter should be placed at the position where the highest value is expected. However, in practice this is not done and often even not possible. In general, the wrist dosemeter is worn at wrist level on one of the two arms, but there is no recommendation about which of the two arms is to be monitored, nor is there on the orientation of the dosemeter. Differences in position are even larger in the case of ring dosemeters, since each user decides which finger the dosemeter is worn on and the orientation with respect to the radiation source.

The data were classified into three categories of medical applications: IR/IC, NM and radiation therapy (TH). In general, the group of IR/IC includes any use of X-rays in diagnostics and therapy, with and without fluoroscopy. The group of NM includes workers in conventional diagnostic NM, position emission tomography (PET), therapy with unsealed pharmaceuticals and radiopharmaceutical units. TH involves workers in $\mathrm{BT}$ and therapy. However, one has to keep in mind that it is difficult to unambiguously identify these three different activities from the collected information because, for example, each dosimetry service has its own labelling method of its customers (workers) which does not strictly correspond to our classification. Besides, it was not possible to distinguish between diagnostic and therapeutic NM since most of NM departments have a single subscription to routine extremity dosimetry for both activities.

Another parameter on which there is no consensus is the reporting level. In Switzerland, Germany, Greece and Poland, the reporting level is $1 \mathrm{mSv}$, whereas in Ireland and Spain it is $0.1 \mathrm{mSv}$, and between 0.1 and $0.3 \mathrm{mSv}$ for France, depending on the dosimetry service. These differences influence the numerical value of the reported mean doses to the exposed workers.

These examples confirm that there is a need for harmonisation of dosimetric practices in extremity monitoring across Europe ${ }^{(7)}$.

In all cases, the reported mean doses were calculated for monitored workers. Of course, the values would have been higher if they had been given for exposed workers (those with doses larger than zero) and, in both cases, they are influenced by the reporting level value. In Germany, the exposed workers represent about $25 \%$ of the monitored workers for IR and $50 \%$ of NM workers. In Spain, the exposed workers are $60 \%$ of those monitored for IR and $85 \%$ for NM.

\section{RESULTS AND DISCUSSION}

\section{Extremity dosimetry in the medical field}

Table 1 shows, for year 2005, the number of monitored workers in the medical field in the seven chosen European countries (rounded numbers), together with the fraction who use extremity dosemeters, detailing the type of dosemeter used. French data include veterinary workers, who represent $6.7 \%$ of the total. Most monitored workers in the medical field wear a

Table 1. Summary of individual monitoring in the medical field for seven European countries in 2005: France (F), Germany (D), Greece (GR), Ireland (IE), Poland (PL) Spain (E) and Switzerland (CH).

\begin{tabular}{|c|c|c|c|c|}
\hline \multirow[t]{2}{*}{ Country } & \multirow{2}{*}{$\begin{array}{l}\text { Number of whole body } \\
\text { monitored workers }\end{array}$} & \multirow{2}{*}{$\begin{array}{l}\text { Workers wearing an } \\
\text { extremity dosemeter }(\%)\end{array}$} & \multicolumn{2}{|c|}{ Workers wearing $(\%)$} \\
\hline & & & Ring dosemeter & Wrist dosemeter \\
\hline $\mathrm{F}$ & $159000^{\mathrm{a}}$ & 5 & 19 & 81 \\
\hline $\mathrm{D}$ & 240000 & 5 & 100 & 0 \\
\hline GR & 9200 & 2 & 0 & 100 \\
\hline IE & 6900 & 5 & 100 & 0 \\
\hline PL & 29200 & 2 & 100 & 0 \\
\hline $\mathrm{E}$ & 43000 & 9 & 5 & 95 \\
\hline $\mathrm{CH}$ & 50800 & 2 & 100 & 0 \\
\hline
\end{tabular}

${ }^{a}$ Including veterinary workers, who represent $6.7 \%$ of the total. 


\section{DONADILLE ETAL.}

whole body dosemeter. However, only a minority, between 2 and $9 \%$, also wear an extremity dosemeter.

\section{Reported extremity doses}

The following paragraphs present the registered mean extremity doses classified for the three medical applications (IR/IC, NM and TH) considered and the type of dosemeters (ring and wrist) used. Although better statistical indicators than the mean doses would be the variability range (minimum and maximum doses) and the median value in each case, these were not provided in the collected data.

\section{Interventional radiology/cardiology}

Table 2 presents the mean annual extremity doses in IR/IC, for year 2005. Mean doses is range from 2.5 to $19.2 \mathrm{mSv}$. In the countries where both ring and wrist dosimetry are used, mean annual doses measured with a ring dosemeter are always higher than those obtained with a wrist dosemeter, differences are a factor of 2 and 7 for Spain and France, respectively. For Greece, the large wrist annual dose is due to two cases of bad practices and is reduced to $1.85 \mathrm{mSv}$ if they are not considered. The second part of the table indicates the number of workers with a mean annual dose higher than $5 \mathrm{mSv}$ and those with a dose higher than $50 \mathrm{mSv}$ for the countries which these data were available from. The percentage of monitored workers which represents each category is shown beside. It can be seen that annual extremity doses above $50 \mathrm{mSv}$ are found in very few cases only.

\section{Nuclear medicine}

Table 3 gives the mean annual extremity doses in NM, for year 2005. Likewise in Table 2, the number of workers receiving doses higher than 5 and $50 \mathrm{mSv}$ is shown. For Germany, the classification has to be interpreted in a different way: the number of workers with doses higher than $5 \mathrm{mSv}(50 \mathrm{mSv})$ actually corresponds to the number with doses higher than $1 \mathrm{mSv}(10 \mathrm{mSv})$. The reported mean annual doses in NM range from 1.9 to $29.1 \mathrm{mSv}$. In the countries in which both ring and wrist dosemeters are used, mean annual doses measured with a ring dosemeter are about four times higher than those obtained with a wrist one. Again, the number of workers with annual doses above $50 \mathrm{mSv}$ is very small.

When comparing the mean doses derived from ring dosemeters for NM with those of IR/IC for the same country, it can be observed that the mean doses are higher for NM than for IR/IC.

\section{Radiation therapy}

There are very few data available for the extremity doses due to TH. Table 4 presents the mean annual extremity doses in $\mathrm{TH}$ for France, Germany and Ireland for year 2005, together with the number of workers receiving doses higher than 5 and $50 \mathrm{mSv}$ in this medical field. As mentioned earlier for Germany, this classification is different. Reported mean annual doses are between 2 and $8 \mathrm{mSv}$ for ring dosemeters and $1.4 \mathrm{mSv}$ for wrist dosemeters. In France, where both ring and wrist dosemeters are used, mean annual doses measured with a ring dosemeter are about six times higher than those with a wrist one.

\section{Comparison with data from literature dedicated studies}

Several dedicated studies dealing with the evaluation of extremity doses in different medical applications were published in the literature. They have been reviewed in a recent publication ${ }^{(5)}$. This review

Table 2. Mean annual extremity doses in IR/IC and number of workers with annual doses above 5 and $50 \mathrm{mSv}$ in 2005.

\begin{tabular}{|c|c|c|c|c|c|c|}
\hline $\begin{array}{l}\text { Type of } \\
\text { extremity } \\
\text { dosemeter }\end{array}$ & Country & $\begin{array}{c}\text { Number of workers } \\
\text { wearing extremity } \\
\text { dosemeters }\end{array}$ & $\begin{array}{c}\text { Reporting } \\
\text { level (mSv) }\end{array}$ & $\begin{array}{c}\text { Mean annual } \\
\text { doses }(\mathrm{mSv})\end{array}$ & $\begin{array}{c}\text { Number of annual } \\
\text { doses }>5 \mathrm{mSv}\end{array}$ & $\begin{array}{l}\text { Number of annual } \\
\text { doses }>50 \mathrm{mSv}\end{array}$ \\
\hline \multirow[t]{6}{*}{ Ring } & $\mathrm{F}$ & 1279 & $0.1-0.3$ & 10.9 & - & - \\
\hline & $\mathrm{D}$ & 7155 & 1 & 2.5 & - & - \\
\hline & IE & 188 & 0.1 & 2.3 & $0(0 \%)$ & $0(0 \%)$ \\
\hline & PL & 585 & 1 & 8.2 & - & $0(0 \%)$ \\
\hline & $\mathrm{E}$ & 50 & 0.1 & 19.2 & $25(50 \%)$ & $10(20 \%)$ \\
\hline & $\mathrm{CH}$ & 407 & 1 & 3.6 & $39(10 \%)$ & $9(2 \%)$ \\
\hline \multirow[t]{3}{*}{ Wrist } & $\mathrm{F}$ & 5302 & $0.1-0.2$ & 1.5 & - & - \\
\hline & $\mathrm{GR}^{\mathrm{a}}$ & 133 & 1 & 17.9 & $7(5 \%)$ & $2(2 \%)$ \\
\hline & $\mathrm{E}$ & 2799 & 0.1 & 8.9 & $654(23 \%)$ & $144(5 \%)$ \\
\hline
\end{tabular}

\footnotetext{
- indicates no data available.

${ }^{\text {a }}$ For Greece the mean annual dose is reduced to $1.85 \mathrm{mSv}$ when two cases of bad-practices are not considered.
} 
USE OF EXTREMITY DOSEMETERS FOR MEDICAL APPLICATIONS

Table 3. Mean annual extremity doses in NM and number of workers with annual doses above 5 and 50 mSv in 2005.

\begin{tabular}{|c|c|c|c|c|c|c|}
\hline $\begin{array}{l}\text { Type of } \\
\text { extremity } \\
\text { dosemeter }\end{array}$ & Country & $\begin{array}{c}\text { Number of workers } \\
\text { wearing extremity } \\
\text { dosemeters }\end{array}$ & $\begin{array}{l}\text { Reporting } \\
\text { level }(\mathrm{mSv})\end{array}$ & $\begin{array}{c}\text { Mean annual } \\
\text { doses }(\mathrm{mSv})\end{array}$ & $\begin{array}{l}\text { Number of annual } \\
\text { doses }>5 \mathrm{mSv}\end{array}$ & $\begin{array}{l}\text { Number of annual } \\
\text { doses }>50 \mathrm{mSv}\end{array}$ \\
\hline \multirow[t]{6}{*}{ Ring } & $\mathrm{F}$ & 314 & $0.1-0.3$ & 12.2 & - & - \\
\hline & $\mathrm{D}^{\mathrm{a}}$ & 3104 & 1 & 7.1 & $78(3 \%)$ & $46(1 \%)$ \\
\hline & IE & 111 & 0.1 & 5.7 & $34(31 \%)$ & $0(0 \%)$ \\
\hline & PL & 143 & 1 & 7.6 & - & $0(0 \%)$ \\
\hline & $\mathrm{E}$ & 129 & 0.1 & 29.1 & $75(58 \%)$ & $23(18 \%)$ \\
\hline & $\mathrm{CH}$ & 404 & 1 & 9 & $119(29 \%)$ & $19(5 \%)$ \\
\hline \multirow[t]{3}{*}{ Wrist } & $\mathrm{F}$ & 862 & $0.1-0.2$ & 3.1 & - & - \\
\hline & GR & 45 & 1 & 1.9 & $3(7 \%)$ & $0(0 \%)$ \\
\hline & $\mathrm{E}$ & 698 & 0.1 & 6.5 & $206(30 \%)$ & $11(2 \%)$ \\
\hline
\end{tabular}

— indicates no data available.

${ }^{\text {a }}$ For Germany, the number of workers with doses larger than $5 \mathrm{mSv}(50 \mathrm{mSv})$, actually corresponds to number of workers with doses larger than $1 \mathrm{mSv}(10 \mathrm{mSv})$.

Table 4. Mean annual extremity doses in TH and number of workers with annual doses above 5 and $50 \mathrm{mSv}$ in 2005.

\begin{tabular}{|c|c|c|c|c|c|c|}
\hline $\begin{array}{l}\text { Type of } \\
\text { extremity } \\
\text { dosemeter }\end{array}$ & Country & $\begin{array}{c}\text { Number of workers } \\
\text { wearing extremity } \\
\text { dosemeters }\end{array}$ & $\begin{array}{l}\text { Reporting } \\
\text { level }(\mathrm{mSv})\end{array}$ & $\begin{array}{c}\text { Mean annual } \\
\text { doses }(\mathrm{mSv})\end{array}$ & $\begin{array}{l}\text { Number of annual } \\
\text { doses }>5 \mathrm{mSv}\end{array}$ & $\begin{array}{l}\text { Number of annual } \\
\text { doses }>50 \mathrm{mSv}\end{array}$ \\
\hline \multirow[t]{3}{*}{ Ring } & $\mathrm{F}$ & 24 & $0.1-0.3$ & 8 & - & - \\
\hline & $\mathrm{D}^{\mathrm{a}}$ & 544 & 1 & 2 & $5(1 \%)$ & $2(0.4 \%)$ \\
\hline & IE & 63 & 0.1 & 4.6 & $28(44 \%)$ & $0(0 \%)$ \\
\hline Wrist & $\mathrm{F}$ & 590 & $0.1-0.2$ & 1.4 & - & - \\
\hline
\end{tabular}

${ }^{\mathrm{a}}$ For Germany, the number of workers with doses larger than $5 \mathrm{mSv}(50 \mathrm{mSv})$, actually corresponds to number of workers with doses larger than $1 \mathrm{mSv}(10 \mathrm{mSv})$.

notably highlighted the fact that significant extremity doses can be reached. In IR/IC, most published estimations of annual extremity doses led to levels smaller than the dose limits, but some authors found higher doses than limits. In conventional diagnostic NM (i.e. scintigraphies carried out mainly with ${ }^{99 \mathrm{~m}} \mathrm{Tc}$ ), published extrapolations give a range of 4 to more than $300 \mathrm{mSv}$ per year. Some studies even report annual extremity doses at the area of skin where the maximum dose is up to a few Sv. Anyhow annual extrapolations published in the literature reached easily few tens to few hundreds $\mathrm{mSv}$ per year.

These observations are in apparent contradiction with the annual reported doses from the seven European countries considered previously. For example, from Table 3, it is shown that the mean annual ring doses range in $5-30 \mathrm{mSv}$, with only few cases presenting doses larger than $50 \mathrm{mSv}$.

These discrepancies are probably due to the fact that (i) the dosemeters may not be systematically worn; (ii) the most exposed workers may not be monitored; and (iii) the dosemeters may be worn at not adapted positions, leading to significant underestimations of the doses.

\section{CONCLUSIONS}

The increasing use of ionising radiation in medicine requires the development of new radiation protection programmes. Large differences between mean annual doses reported in national dosimetric data bases and dosimetry services, and measured doses in pilot research studies are found. This shows that the present extremity dose monitoring underestimates the real radiological risk of exposed medical staff and that no particular effort on the identification of the most exposed area is done. Nevertheless, the mean values recorded with ring dosemeters indicate that this kind of extremity dosemeters is a better estimator of the maximum doses to the extremity than wrist ones.

In spite of the difficulties involved in the routine monitoring of extremities, the development of a systematic study which could identify 'the most exposed area' for typical or more common activities could enable agreement on general requirements that could be followed by most of the users, and thus ensure adequate harmonisation within the EU member states. 


\section{DONADILLE ETAL.}

Finally, it should be pointed out that it would be very desirable to complete with extremity doses general international individual monitoring databases, such as UNSCEAR, ESOREX or ISOE.

\section{ACKNOWLEDGEMENTS}

The authors acknowledge the representatives of regulatory bodies and dosimetry services for sharing the information used in this article.

\section{REFERENCES}

1. Council Directive 96/29/EURATOM of 13 May 1996 laying down basic safety standards for the protection of the health of workers and the general public against the dangers arising from ionizing radiations. Off. J. Eur. Commun. 39L, 159 (1996).

2. International Commission on Radiological Protection. 1990 Recommendations of the International Commission on Radiological Protection. ICRP Publication 60,
Annals of the ICRP 21(1-3) (Oxford: Pergamon Press) (1992).

3. International Commission on Radiations Units and Measurements. Conversion Coefficients for use in Radiological Protection Against External Radiations. ICRU Report 57 (Bethesda, MD 20814: ICRU Publications) (1998).

4. Carinou, E. et al. Intercomparison on measurements of the personal dose equivalent, $H_{p}(0.07)$, by extremity ring dosemeters in medical fields. Radiat. Meas. 43, 565-570 (2008).

5. Vanhavere, F., Carinou, E., Donadille, L., Ginjaume, M., Jankowski, J., Rimpler, A. and Sans Merce, M. An overview on extremity dosimetry in medical applications. Radiat. Prot. Dosim. 129, 350-355 (2008).

6. Ginjaume, M. et al. Extremity ring dosimetry intercomparison in reference and workplace fields. Radiat. Prot. Dosim. (2008) (this volume).

7. Kamenopoulou, V. et al. Aspects of harmonisation of individual monitoring for external radiation in Europe: Conclusions of a EURADOS action. Radiat. Prot. Dosim. 118, 139-143 (2006). 